\title{
Lungs' Microscopic Patterns of Vessels in Patients Deceased with or by SARS-CoV-2 Infection
}

\author{
Francesco Lupariello ${ }^{1}$, Francesca Vairano ${ }^{2}$, Giuliana Mattioda ${ }^{2}$, Federica Mirri ${ }^{2}$, Alessandro Gabriele ${ }^{2}$, \\ Giancarlo Di Vella ${ }^{3}$ \\ ${ }^{1}$ Researcher and Assistant Professor, ${ }^{2}$ Scientist, ${ }^{3}$ Full Professor, Department of Public Health Sciences and \\ Pediatrics-Medico-Legal Unit - "University of Turin”; Corso Galileo Galilei 22, 10126 Torino, Italy
}

\begin{abstract}
Background: Even If Specific mechanisms are not completely understood, several studies highlighted Severe Acute Respiratory Syndrome Coronavirus 2 (SARS-CoV-2) ability to alter vascular homeostasis. In the literature, multiple reports of microscopic pulmonary findings of vascular structures in patients deceased by or with SARS-Cov-2 infection are available. Nevertheless, the scientific literature lacks a systematic analysis of these findings. Methods: the authors realized a systematic review of the literature in order to identify common microscopic patterns representative of pulmonary vascular damage: useful data for pathologists in clinical and forensic settings. The research yielded 23 articles (79 total cases). Quali/ quantitative analysis was carried out. Conclusion: the review allowed to identify vascular thrombosis (especially in lesser caliber vessels) as common microscopic pattern. The recurrence of this pattern was confirmed by scientific literature data which demonstrate SARS-CoV-2 ability to interfere with coagulation cascade. Other meaningful microscopic findings were also discussed, even if their low frequency in study population did not allow to define them as common.
\end{abstract}

Keywords: COVID19; endothelium; forensics; lung parenchyma; pathology;SARS-CoV-2; vessels

\section{Introduction}

Even if specific mechanisms are not completelyunderstood, several studies highlightedSevere Acute Respiratory Syndrome Coronavirus 2 (SARSCoV-2) ability to alter vascular homeostasis ${ }^{1-4}$. Pulmonary vascular damage seems to have a fundamental rolein the aforementioned phenomenon, because vascular structures (especiallythe endothelium) are considered as the anatomical substrate in which coagulative, immune, and inflammatory balances interact ${ }^{2,5}$. Thus, according to the literature, the same vascular damage caused by the virus can simultaneously determine coagulation's over-activation, improper cytokine release (cytokine storm), and immune system alterations. Several authors stated that the latter events constitute foundation for the progression of Coronavirus Disease 2019(COVID19) ${ }^{2,4}$.
In the literature, multiple reports of microscopic pulmonary findings of vascular structures in patients deceased by or with SARS-Cov-2 infection are available ${ }^{1,3,4}$. Nevertheless, the scientific literature lacks a systematic analysis of these findings. Their systematic study would be fundamental because it may allow to identify common microscopic patterns representative of pulmonary vascular damage: useful data for pathologists in clinical and forensic settings. For these reasons, the authors realized a systematic review of the literature in order to identify the aforementioned data, and to propose their systematic analysis in the light of the scientific literature.

\section{Materials and Methods}

At first, asystematic review of the scientific literature was conductedin order to identify articles containing pulmonary histologicaldata of deceased people with positivity for Sars-CoV-2 infection. The 
research was performed on Medline electronic database (until November 10th, 2020) using the following algorithm: [histology AND (Sars-Cov-2 OR Covid19)]. The following inclusion criteria were used:articles written in English;articles containing the report of one or more cases in which the deceased had ante-mortem/ post-mortem positivity for Sars-CoV-2 infection;articles reporting specific pulmonary histologicdata for each case.On the contrary, articles containing generic summaries/descriptions of microscopic evidences of more cases were excluded.
The research yielded 2,152 potentially relevant articles. Among them, 33 articles and 3 crossreferencesmatched the aforementioned criteria(Table $1)^{3,6-40}$. Then, the36articles were analysed in order toidentify onlythe cases in which specific microscopic findings of vascular structures were described. This analysis yielded 23 articlesthat underwent full review (Table 1) 3 ,6-8,10,15-20,22,26,27,30,31,34-40. Collected data of the latter articles are available in Table 2 - 4. They were finally reviewed in the light of the scientific literature. Excel statistic formulas were used to calculate Average, Standard Deviation, Median, and Mode.

Table 1: Number of Articles Included/Excluded for pulmonary microscopic findings

\begin{tabular}{|c|c|}
\hline Exclusion/Inclusion & Number ofarticles \\
\hline Excluded reading the title & 1622 \\
\hline Excluded reading the abstract & 207 \\
\hline Excluded reading the entire article & 265 \\
\hline Not in English & 25 \\
\hline Positive for pulmonary microscopic findings & 33 \\
\hline Cross references positive for pulmonary microscopic findings & 3 \\
\hline Reviewed articles (positive for microscopic vascular findings) & 23 \\
\hline
\end{tabular}

Table 2: Summary of the most common comorbidities

\begin{tabular}{|c|c|}
\hline Comorbidity & Number of cases \\
\hline Diabetes & 42 \\
\hline Heart failure & 36 \\
\hline Obesity & 17 \\
\hline Aorticstenosis & 8 \\
\hline Coronaryarterydisease & 8 \\
\hline Kidneyfailure & 7 \\
\hline Hypertension & 6 \\
\hline Atrialfibrillation & 6 \\
\hline Hyperlipidemia & 5 \\
\hline Chronicobstructivepulmonarydisease & 4 \\
\hline Dyslipidemia & 3 \\
\hline Cardiovasculardisease & 3 \\
\hline Ischemiccardiomyopathy & 3 \\
\hline Obstructivesleep apnea syndrome & 2 \\
\hline Congestive heartfailure & 2 \\
\hline Dementia & \\
\hline
\end{tabular}


Table 3: Quali/quantitative representation of vascular microscopic findings

\begin{tabular}{|c|c|c|}
\hline Vascularlocalization & Findings & Number of cases \\
\hline Peri-vascularfindings & $\begin{array}{c}\text { LC infiltrate } \\
\text { Genericinflammatory infiltrate } \\
\text { Fibrin }\end{array}$ & $\begin{array}{c}5(1 / 5 \mathrm{CD} 3+) \\
4 \\
2\end{array}$ \\
\hline Vascularfindings in vessels & $\begin{array}{c}\text { Generic thrombi } \\
\text { Fibrin thrombi } \\
\text { Platelet thrombi } \\
\text { Hyaline thrombi } \\
\text { Congestion } \\
\text { Inflammatory infiltration } \\
\text { Fibrin } \\
\text { Megakaryocytes } \\
\text { Platelets and NET } \\
\text { Platelets } \\
\text { Complement } \\
\text { TE signs }\end{array}$ & $\begin{array}{c}37(25 / 37 \text { micro-thrombi) } \\
7 \\
3(1 / 3 \text { CD } 61+) \\
2 \\
28 \\
6 \\
3 \\
3 \\
3(\mathrm{PF} 4+\text { and } \mathrm{H} 31+) \\
1(\mathrm{CD} 61+) \\
2(1 / 25 b-9+; 1 / 2 \mathrm{C} 4 \mathrm{~d}+, \mathrm{C} 3 \mathrm{~d}+, \mathrm{C} 5 \mathrm{~b}-9+) \\
3\end{array}$ \\
\hline Vascularwalls & $\begin{array}{c}\text { Hyperplasia } \\
\text { Endotheliitis } \\
\text { Necrosis } \\
\text { Apoptotic bodies associated with the } \\
\text { endothelium }\end{array}$ & $\begin{array}{c}5 \\
5 \text { (3/5 aspecific; } 1 / 5 \text { lymphocytic; } 1 / 5 \\
\text { neutrophilic) } \\
2 \\
1\end{array}$ \\
\hline Neovascularization & Neovascularization & 1 \\
\hline
\end{tabular}

LC: lymphocyte, NET: neutrophil extracellular trap, TE: thromboembolism

Table 4: Vessels' caliber in case of thrombi

\begin{tabular}{|c|c|c|}
\hline & Caliber & Number of cases \\
\hline & & 1 \\
Caliber of vessels characterized by & Large & 13 \\
thrombi & Medium & 6 \\
& Small/capillaries & 19 \\
\hline
\end{tabular}

\section{Results}

The 36 articles contained the description of 142 cases. Among them, in 79/142 cases specific microscopic findings of vascular structures were described. Main characteristics of these cases are summarized in Table
2 - 4. Average age of the 79 cases was 69.64 years old (Standard Deviation 13.81, Median 73, Mode 71). Their sex distribution was:male 52, female 23, 4 not specified. The most common comorbidities werediabetes (42), hypertension (36 cases), and obesity (17 cases).Quali/ 
Medico-legal Update, October-December 2021, Vol.21, No. $4 \mathbf{1 4 3}$

quantitative analysis of vascular microscopic findings issummarized in Table 3and4.

\section{Discussion}

In the literature, multiple reports of microscopic pulmonary findings of vascular structures in patients deceased by or with SARS-Cov-2 infection are available ${ }^{1-4}$. However, these reports usually refer to single cases or small case series ${ }^{1,3}$. Thus, until now the scientific literature lacks a systematic analysis of these findings. In particular,common microscopic patterns of pulmonary vascular involvement/damage are not described. The present review pointed out the following indications on this topic.

\section{COVID19 and coagulative thromboticmicroscopic patterns}

The results of the present review did not allow to identify a vascular pattern that was present in all reviewed cases. However, common findings were intravascular thrombi that recurred 49 times. The most part of themwere described as micro-thrombi and/or identified in medium/ small/capillary vessels. At microscopic evaluation, large vessel involvement was reported only in one case. In the scientific literature,pulmonary microvascular thrombosis was early suggested as responsible for COVID19 progression ${ }^{41,42}$, observing that infected patients were characterized by "profound hypoxia which was out of proportion to the preserved lung mechanics suggestive of significantpulmonary shunting, raising the possibility of a lung injury mechanism different from that oftraditional ARDS"2.This statement was confirmed by Ackerman and colleagues who compared lungs of influenza Ainfectedpatients against SARSCoV-2 ones, revealing as micro-thrombi were more prevalent in COVID-19 ${ }^{1}$. It is well known that viral infections - via multiple pathways - can impair the coagulation cascade causing haemorrhagic and/or thrombotic complications ${ }^{2}$. Indeed, in COVID19 one of the most common manifestations of altered coagulation cascade is the elevation of D-Dimer that is "a marker of coagulationcascade activation in the microvascular beds which has been shown to be pathologically elevated in $46 \%$ of SARS-CoV-2-infected patients and in 56\% of those with severe disease" ${ }^{2}$. Typical features of coagulopathy in SARS-CoV-2 infected patients (i.e.DDimer, fibrinogen, von Willebrand factor, and VIII factor elevation, mostly normal or slightly depressedpartial thromboplastin time(PTT), variable variation of platelet count, and normal XIa factor)suggest the prevalent activation of extrinsic coagulation cascade ${ }^{2}$. The latter is also known as the tissue factor pathway because it is triggered by tissue trauma and endothelial activation. This event causes the expression of high levels of tissue factor on vascular cells, resulting in activation of coagulation factors ${ }^{2}$.Several authorssuggested direct and/or indirect SARS-CoV-2 ability to cause vascular tissue trauma/endothelial activation ${ }^{2,3,43}$. The direct activation hypothesis is based on SARS-CoV-2 ability to infect the host through the angiotensin converting enzyme 2(ACE2) receptor which is also expressed by endothelial cells ${ }^{3}$. On the contrary, the indirect activation one has foundation in the so-calledcytokine storm (principally IL-1 and IL-6 elevation) caused by the virus ${ }^{2}$.

In addition, it is important to note that in two cases the authors reported vascular deposits of $\mathrm{C} 5 \mathrm{~b}$ 9at immunocytochemistry, demonstrating complement activation (especially the alternative pathway). The latter finding is particularly suggestive because it is well known that complement system cross talks with the coagulation cascade at different levels ${ }^{2,44,45}$. In particular, the complement can induce tissue factor expression on the endothelium, and it can suppress mast cells' fibrinolytic activity causing clot progression ${ }^{2,46}$. Thus, this phenomenon can be considered as a possible cause/ concurrent cause of the aforementioned thrombosis in COVID19. Similar considerations can be related to the so-called neutrophil extracellular traps (NETs) that were identified in three cases at immunohistochemistry.NETs are principally composed by decondensed chromatin (DNA and histones) that is released by neutrophiles to immobilize microorganisms when they are activated by strong stimulations ${ }^{43}$. Recent studies highlighted NET's immune-thrombosis ability in COVID19, demonstrating that "NET release is positively correlated with invivo 
thrombotic potency in COVID-19"47. In particular, these complexes would be capable to activate tissue factor/thrombinaxisand platelets ${ }^{43,47}$.Indeed, different authors recognized NETs as linking factors between inflammation, coagulation, and thrombosis (locally and systemically $)^{43,48}$.In addition, from a clinical point of view the aforementioned data are particularly meaningful because they seem to agree with the recent manuscript byZuo and colleagues whoreported the correlation between cell-free-DNA levels (NETosis) and acuity of COVID19, inflammatory response, and need for mechanical ventilation ${ }^{49}$.

Talking about megakaryocytes, multiple studies suggested their common presence inSARSCoV-2 affected lungs ${ }^{50}$. In the present review, megakaryocytes'population was identified in vessels in three cases. Despite this small number, the latter microscopic finding seems to agree with the scientific literature that highlightedmegakaryocytes'altered functions in SARS-CoV-2 disease. In particular, Bernardes and colleagues recently "hypothesized that altered presence and function of MKsmight be a distinct feature of COVID-19", describing higher number of megakaryocytes in severe COVID19 and reporting "an increased metabolic activityof MKs along the disease trajectory compared with that inhealthy controls" $" 50$. Thus, megakaryocytes may have a specific role in SARS-CoV-2 infection, however neither literature data nor the present review pointed out a common vascular microscopic pulmonary pattern of these cells.

In the light of the above, the aforementioned results allowed to identify vascular thrombosis (especially in lesser caliber vessels) as common microscopic pattern of pulmonary parenchyma in SARS-CoV-2 infected patients in lethal cases. The recurrence of this pattern is confirmed by scientific literature data which demonstrate SARS-CoV-2 ability to interfere with coagulation cascade. However, so farSARS-CoV-2 pro-coagulant mechanisms are not completely understood. In addition, it is not yet defined the reasons why thrombosis activation tends to involve especially lessercaliber vessels.

\section{COVID19 and vascular/endothelialinflammatory} patterns

Lymphocytic endotheliitis and apoptotic bodies are already described in surgical tissue specimens of SARSCoV-2 infected patients. These findings are considered as the result viral interaction with endothelial cells. Even if SARS-CoV-2 ability to infect engineered human blood vessels - binding ACE 2 receptors of endothelial cells - is already demonstrated ${ }^{51}$, it is important to highlight that apoptosis may not be triggered only by viral entry. The binding with endothelial cells' surface can activate apoptotic pathway signaling ${ }^{52}$. In the present review, apoptotic bodies within the endothelium were described in one case. Thus, the latter finding cannot be identified as a common vascular microscopic pattern, even if literature data report direct and/orindirect viral activityon the endothelium. Similar considerations can be related to endotheliitis that was reported in 5 cases. In particular, in $2 / 5$ cases the authors respectively described this inflammatory phenomenonas lymphocytic and neutrophilic.Immunology of COVID19 is not yet completely understood ${ }^{5}$, even if preliminary data suggest the following considerations on lymphocytic and neutrophilic cells:as mentioned above, neutrophilic cells seem to be implicated in NET formations; several reports pointed out the occurrenceof $\mathrm{T}$ lymphopenia (reduction of $\mathrm{CD}^{+}$and $\mathrm{CD} 8^{+}$counts in peripheral blood in moderate and severe COVID19); on the contrary, the scientific literature highlighted that SARS-CoV-2 elicits a significant $\mathrm{B}$ cell response, determining rapid increase of virus-specific IgM, IgG and IgA, and neutralizing IgG antibodies $^{5}$. Thus, the localization of lymphocytes and neutrophilesin correspondence with the endothelium is consistent with literature data, even if - especially for lymphocytes - in the reviewed articles there were few immunohistochemistry studies which allowed to identify cells'specific sub-types.In the present review, 15 cases were characterized by vascular/peri-vascular inflammatory infiltration. Among them in 5/15 cases the authors specifically described lymphocytes as prevalent population; on the contrary, in 10/15 cases they did not described cells'specific pattern. In addition, in 
only $1 / 15$ case at immunohistochemistry lymphocytes were characterized as $\mathrm{CD}^{+}$. Thus, even if these data are consistent with literature's indications, it was not possible to identify a specific vascular/peri-vascular microscopic pattern.

In the light of the above, the aforementioned results allow to state that - as for COVID19 immunology until nowcommoninflammatory microscopic patterns of endothelial/vascular pulmonary structures are not clearly identified in SARS-CoV-2 infected patients in lethal cases.

\section{COVID19 and pulmonary thromboembolism}

In the scientific literature, pulmonary thromboembolism (PTE) was reported as a common finding in patients admitted to intensive care units. For example, in a cohort study of 107 patients the $20 \%$ was affected by PTE despite thromboprophylaxis ${ }^{53}$. The comparison of this cohort "to a similar one hospitalized a year earlier and a smaller influenza cohort from the prior season" yielded the following result: "the frequency of PE was twice as high in the COVID group despite less computed tomography (CT)angiogram tests performed" 53 . In the present review, even if multiple findings of thrombosis (especially micro-thrombosis) were identified, specific signs of PTE were described in 3 cases. Thus, the present review did not allow to define microscopic PTE signs as common in lung parenchyma of SARS-CoV-2 deceased patients.

\section{COVID19 and neovascularization}

Pulmonary microscopic neovascularization was reported in one case. Thus, this finding cannot be considered common of SARS-CoV-2 infection in deceased individuals. However, Ackerman and colleagues recently pointed out the recurrence - at transmission electron microscopy - of new blood vessel formation by enhanced intussusceptive angiogenesis in lungs of patients who died from COVID19 ${ }^{1}$. This type of angiogenesis does not occur by conventional sprouting of new vessels, but it is characterized by "thepresence of a pillar or post spanning the lumenof the vessel"1. In addition, the authors reported that vascular angiogenesis allowed to distinguish "the pulmonary pathobiologyof Covid-19 from that of equally severe influenza virus infection"1, suggesting that "althoughtissue hypoxia was probably a common featurein the lungs from both these groups of patients, we speculate that the greater degree of endothelialitisand thrombosis in the lungs from patientswith Covid-19 may contribute to the relativefrequency of sprouting and intussusceptiveangiogenesis observed in these patients"1. Even if further studies are necessary in order to clearly understand this phenomenon (especially its relations with the clinical course of the disease), the abovementioned statement is confirmed by the high number of cases in which vascular thrombosis and/or endotheliitis were described in the present review.

\section{COVID19 and vascular wall hyperplasia}

Significantgrowth ofvascular endothelial and myointimalcells was reported in skin biopsies of cutaneous lesions during SARS-CoV-2infection period ${ }^{54}$. The authors reported a skinvasculopathic reaction pattern, suggesting "amicrovascular process with vascular wall cell injury"and vascularcell proliferation "confirmed by the increased numbers ofreplicating cells positive stained for Ki67 and Cyclin D1 found inboth vascular endothelial cells and myointimal vascular cells" ${ }^{54}$.In addition, they pointed out that the possible underlying pathophysiological process would rely on vascular response to hypoxic insult ${ }^{54,55}$, which is considered as a fundamental feature of COVID19². The present review identified vascular wall hyperplasia of pulmonary parenchyma in 5 cases.However, these cases - especially in relation to their low number - did not allow to identify specific microscopic pattern which could be useful to understand the underlying pathophysiological process or to define these findings as common in in SARS-CoV-2 infected patients in lethal cases. Further studies will be necessary on this topic.

\section{Conclusions}

This review representsthe first systematic analysis of microscopic pulmonary findings of vascular structures 
in patients deceased by or with SARS-Cov-2 infection. It allowed to identify vascular thrombosis (especially in lesser caliber vessels) as common microscopic pattern of pulmonary parenchymain these patients. The recurrence of this pattern is confirmed by scientific literature data which demonstrate SARS-CoV-2 ability to interfere with the coagulation cascade. However, until now SARSCoV-2 pro-coagulant mechanisms are not completely understood. In addition, it is not yet defined the reason why thrombosis activation tends to involve especially less caliber vessels.

This analysis also pointed out the recurrence of other meaningful pulmonary microscopic findings of vascular structures. So far, they cannot be defined as common in SARS-CoV-2 infected patients in lethal cases; indeed, further studies will be necessary to reach this goal.

Limitations of the present review are related to the non-homogeneityof microscopic evaluations of histologic slides. In particular, the aforementioned results came from operators who have different backgrounds and different ways to describe microscopic pulmonary findings. Indeed, in the present review the most difficult task relied on interpretation and aggregation of the same/similar microscopic findings in quali/quantitative groups that would have allowed to implement a coherent systematic analysis avoiding results' distortions. For this reason, the authors divided microscopic findings in few and simple categories (peri-vascular findings, vascular findings in vessels, vascular walls, and neovascularization) in order to reach this goal.

Another limitation was related to the impossibility to clearly distinguish between patients deceased with or by SARS-CoV-2 infection.Thus, all indications of the present review are referred to SARS-CoV-2 infected patients in lethal cases. In addition, it cannot be excluded that some microscopic results could be the manifestation of other comorbidities and/or pathophysiologic processes. For this reason, the authors also proposed a systematic analysis of results in the light of the scientific literature, in order to verify their coherency with the available literature data.

\section{Acknowledgements: Nil.}

Ethical Clearance: Taken from University of Turin ethical committee.

Source of funding: Self-Funding.

\section{Conflict of Interest: Nil}

\section{References}

1. Ackermann M, Verleden SE, Kuehnel M, et al. Pulmonary Vascular Endothelialitis, Thrombosis, and Angiogenesis in Covid-19. N Engl J Med. 2020;383(2):120-128.doi:10.1056/nejmoa2015432

2. Kamel MH, Yin W, Zavaro C, Francis JM, Chitalia VC. Hyperthrombotic Milieu in COVID-19 Patients. Cells. 2020;9(11). doi:10.3390/cells9112392

3. Varga Z, Flammer AJ, Steiger P, et al. Endothelial cell infection and endotheliitis in COVID-19. Lancet. 2020;395(10234):1417-1418. doi:10.1016/ S0140-6736(20)30937-5

4. Magro CM, Mulvey J, Kubiak J, et al. Severe COVID-19: A multifaceted viral vasculopathy syndrome. Ann Diagn Pathol. 2021;50:151645. doi:10.1016/j.anndiagpath.2020.151645

5. Vabret N, Britton GJ, Gruber C, et al. Immunology of COVID-19: Current State of the Science. Immunity. 2020;52(6):910-941. doi:10.1016/j. immuni.2020.05.002

6. Buja LM, Wolf D, Zhao B, et al. The emerging spectrum of cardiopulmonary pathology of the coronavirus disease 2019 (COVID-19): Report of 3 autopsies from Houston, Texas, and review of autopsy findings from other United States cities. Cardiovasc Pathol. 2020;48. doi:10.1016/j. carpath.2020.107233

7. Magro C, Mulvey JJ, Berlin D, et al. Complement associated microvascular injury and thrombosis in the pathogenesis of severe COVID-19 infection: A report of five cases. Transl Res. 2020;220:1-13. doi:10.1016/j.trs1.2020.04.007

8. Recalde-Zamacona B, García-Tobar L, Argueta A, et al. Histopathological findings in fatal COVID-19 severe acute respiratory syndrome: Preliminary experience from a series of 10 Spanish patients. Thorax. 2020;75(12):1116-1118. doi:10.1136/ thoraxjnl-2020-215577

9. Scendoni R, Marchesani F, Cannovo N, Fedeli 
P, Cingolani M. Histopathology of COVID-19 pneumoniain two non-oncological, non-hospitalised cases as a reliable diagnostic benchmark. Diagn Pathol. 2020;15(1). doi:10.1186/s13000-02000990-4

10. Stone JR, Tran KM, Conklin J, Mino-Kenudson M. Case 23-2020: A 76-Year-Old Woman Who Died from Covid-19. N Engl J Med. 2020;383(4):380387. doi:10.1056/nejmcpc2004974

11. FarkashEA, Wilson AM, Jentzen JM.Ultrastructural evidence for direct renal infection with sarscov-2. J Am Soc Nephrol. 2020;31(8):1683-1687. doi:10.1681/ASN.2020040432

12. Sekulic M, Harper H, Nezami BG, et al. Molecular detection of SARS-CoV-2 infection in FFPE samples and histopathologic findings in fatal SARSCoV-2 cases. Am J Clin Pathol. 2020;154(2):190200. doi:10.1093/AJCP/AQAA091

13. Heinrich F, Sperhake JP, Heinemann A, et al. Germany's first COVID-19 deceased: a 59-yearold man presenting with diffuse alveolar damage due to SARS-CoV-2 infection. Virchows Arch. 2020;477(3):335-339. doi:10.1007/s00428-02002872-y

14. Youd E, Moore L. COVID-19 autopsy in people who died in community settings: The first series. J Clin Pathol. 2020;73(12):840-844. doi:10.1136/ jclinpath-2020-206710

15. Bradley BT, Maioli H, Johnston R, et al. Histopathology and ultrastructural findings of fatal COVID-19 infections in Washington State: a case series. Lancet. 2020;396(10247):320-332. doi:10.1016/S0140-6736(20)31305-2

16. Bösmüller $\mathrm{H}$, Traxler $\mathrm{S}$, Bitzer $\mathrm{M}$, et al. The evolution of pulmonary pathology in fatal COVID-19 disease: an autopsy study with clinical correlation. Virchows Arch. 2020;477(3):349-357. doi:10.1007/s00428-020-02881-x

17. Shao C, Liu H, Meng L, et al. Evolution of severe acute respiratory syndrome coronavirus 2 RNA test results in a patient with fatal coronavirus disease 2019: a case report. Hum Pathol. 2020;101:82-88. doi:10.1016/j.humpath.2020.04.015

18. Grimes Z, Bryce C, Sordillo EM, et al. Fatal Pulmonary Thromboembolism in SARS-CoV-2Infection. Cardiovasc Pathol. 2020;48:107227. doi:10.1016/j.carpath.2020.107227

19. The first COVID-19 autopsy in Spain performed
Medico-legal Update, October-December 2021, Vol.21, No. 4147 during the early stages of the pandemic. Rev Esp Patol. 2020;53(3):182-187. doi:10.1016/j. patol.2020.05.004

20. Suess C, Hausmann R. Gross and histopathological pulmonary findings in a COVID-19 associated death during self-isolation. Int $J$ Legal Med. 2020;134(4):1285-1290. doi:10.1007/s00414-02002319-8

21. Cîrstea AE, Buzulică RL, Pirici D, et al. Histopathological findings in the advanced natural evolution of the sars-cov-2 infection. Rom J Morphol Embryol. 2020;61(1):209-218. doi:10.47162/RJME.61.1.23

22. Aguiar D, Lobrinus JA, Schibler M, Fracasso T, Lardi C. Inside the lungs of COVID-19 disease. Int J Legal Med. 2020;134(4):1271-1274. doi:10.1007/ s00414-020-02318-9

23. Zhang H, Zhou P, Wei Y, et al. Histopathologic changes and SARS-COV-2 immunostaining in the lung of a patient with coviD-19. Ann Intern Med. 2020;172(9):629-632. doi:10.7326/M20-0533

24. Barton LM, Duval EJ, Stroberg E, Ghosh S, Mukhopadhyay S. COVID-19 Autopsies, Oklahoma, USA. Am $J$ Clin Pathol. 2020;153(6):725-733. doi:10.1093/ajcp/aqaa062

25. Xu Z, Shi L, Wang Y et al. Xu Z, Shi L, Wang Y, et al. Pathological findings of COVID-19 associated with acute respiratory distress syndrome [published correction appears in Lancet Respir Med. 2020 Feb 25;:]. Lancet Respir Med. 2020;8(4):420-422. doi:10.1016/S2213-2600(20)30076-X. Lancet Respir Med. 2020;8(feb 25):420-422. https://doi. org/10.1016/ S2213-2600(20)30076-X

26. Yao XH, He ZC, Li TY, et al. Pathological evidence for residual SARS-CoV-2 in pulmonary tissues of a ready-for-discharge patient. Cell Res. 2020;30(6):541-543. doi:10.1038/s41422-0200318-5

27. Tian S, Xiong Y, Liu H, et al. Pathological study of the 2019 novel coronavirus disease (COVID-19) through postmortem core biopsies. Mod Pathol. 2020;33(6):1007-1014. doi:10.1038/s41379-0200536-x

28. Li S, Jiang L, Li X, et al. Clinical and pathological investigation of patients with severe COVID-19.JCI Insight. 2020;5(12). doi:10.1172/jci.insight.138070

29. Lacy JM, Brooks EG, Akers J, et al. COVID-19: Postmortem Diagnostic and Biosafety 
Considerations. Vol 41.; 2020. doi:10.1097/ PAF.0000000000000567

30. Navarro Conde P, Alemany Monraval P, Medina Medina $\mathrm{C}$, et al. Autopsy findings from the first known death from Severe Acute Respiratory Syndrome SARS-CoV-2 in Spain. Rev Esp Patol. 2020;53(3):188-192. doi:10.1016/j. patol.2020.04.002

31. Konopka KE, Nguyen T, Jentzen JM, et al. Diffuse alveolar damage (DAD) resulting from coronavirus disease 2019 Infection is Morphologically Indistinguishable from Other Causes of DAD. Histopathology. 2020;77(4):570-578. doi:10.1111/ his. 14180

32. Bryce C, Grimes Z, Pujadas E, et al. Pathophysiology of SARS-CoV-2: targeting of endothelial cells renders a complex disease with thrombotic microangiopathy and aberrant immune response. The Mount Sinai COVID-19 autopsy experience. Published online 2020. doi:10.1101/2020.05.18.20099960

33. Lax SF, Skok K, Zechner P, et al. Pulmonary Arterial Thrombosis in COVID-19 With Fatal Outcome: Results From a Prospective, SingleCenter, Clinicopathologic Case Series. Ann Intern Med. 2020;173(5):350-361. doi:10.7326/M202566

34. Wichmann D, Sperhake JP, Lütgehetmann M, et al. Autopsy Findings and Venous Thromboembolism in Patients With COVID-19: A Prospective Cohort Study. Ann Intern Med. 2020;173(4):268-277. doi:10.7326/M20-2003

35. von Weyhern $\mathrm{CH}$, Kaufmann I, Neff $\mathrm{F}$, Kremer M. Early evidence of pronounced brain involvement in fatal COVID-19 outcomes. Lancet. 2020;395(10241):e109. doi:10.1016/S01406736(20)31282-4

36. Martines RB, Ritter JM, Matkovic E, et al. Pathology and pathogenesis of SARS-CoV-2 associated with fatal coronavirus disease, united states. Emerg Infect Dis. 2020;26(9):2005-2015. doi:10.3201/eid2609.202095

37. Flikweert AW, Grootenboers MJJH, Yick DCY, et al. Late histopathologic characteristics of critically ill COVID-19 patients: Different phenotypes without evidence of invasive aspergillosis, a case series. J Crit Care. 2020;59:149-155. doi:10.1016/j. jcrc.2020.07.002
38. Middleton EA, He XY, Denorme F, et al. Neutrophil extracellular traps contribute to immunothrombosis in COVID-19 acute respiratory distress syndrome. Blood. 2020;136(10):1169-1179. doi:10.1182/ blood.2020007008

39. Grosse C, Grosse A, Salzer HJF, Dünser MW, Motz R, Langer R. Analysis of cardiopulmonary findings in COVID-19 fatalities: High incidence of pulmonary artery thrombi and acute suppurative bronchopneumonia. Cardiovasc Pathol. 2020;49. doi:10.1016/j.carpath.2020.107263

40. Ducloyer M, Gaborit B, Toquet C, et al. Complete post-mortem data in a fatal case of COVID-19: clinical, radiological and pathological correlations. Int $J$ Legal Med. 2020;134(6):2209-2214. doi:10.1007/s00414-020-02390-1

41. Leisman DE, Deutschman CS, Legrand M. Facing COVID-19 in the ICU: vascular dysfunction, thrombosis, and dysregulated inflammation. Intensive Care Med. 2020;46(6):1105-1108. doi:10.1007/s00134-020-06059-6

42. Gattinoni L, Coppola S, Cressoni M, Busana M, Rossi S, Chiumello D. COVID-19 does not lead to a "typical" acute respiratory distress syndrome. $\mathrm{Am}$ J Respir Crit Care Med. 2020;201(10):1299-1300. doi:10.1164/rccm.202003-0817LE

43. Becker RC. COVID-19 update: Covid-19associated coagulopathy. J Thromb Thrombolysis. 2020;50(1):54-67. doi:10.1007/s11239-02002134-3

44. Merle NS, Church SE, Fremeaux-Bacchi V, Roumenina LT. Complement system part I molecular mechanisms of activation and regulation. Front Immunol. 2015;6(JUN). doi:10.3389/ fimmu. 2015.00262

45. Merle NS, Noe R, Halbwachs-Mecarelli L, Fremeaux-Bacchi V, Roumenina LT. Complement system part II: Role in immunity. Front Immunol. 2015;6(MAY). doi:10.3389/fimmu.2015.00257

46. Ikeda $K$, Nagasawa $K$, Horiuchi $T$, Tsuru $T$, Nishizaka H, Niho Y. C5a induces tissue factor activity on endothelial cells. Thromb Haemost. 1997;77(2):394-398. doi:10.1055/s-0038-1655974

47. Skendros P, Mitsios A, Chrysanthopoulou A, et al. Complement and tissue factor-enriched neutrophil extracellular traps are key drivers in COVID-19 immunothrombosis. J Clin Invest. 2020;130(11):6151-6157. doi:10.1172/JCI141374 
48. Li B, Liu Y, Hu T, et al. Neutrophil extracellular traps enhance procoagulant activity in patients with oral squamous cell carcinoma. J Cancer Res Clin Oncol. 2019;145(7):1695-1707. doi:10.1007/ s00432-019-02922-2

49. Zuo Y, Yalavarthi S, Shi H, et al. Neutrophil extracellular traps in COVID-19. JCI Insight. 2020;5(11). doi:10.1172/jci.insight.138999

50. Bernardes JP, Mishra N, Tran F, et al. Longitudinal multi-omics analyses identify responses of megakaryocytes, erythroid cells and plasmablasts as hallmarks of severe COVID-19 trajectories. Immunity. 2020;53(6). doi:10.1016/j. immuni.2020.11.017

51. Monteil V, Kwon $\mathrm{H}$, Prado P, et al. Inhibition of SARS-CoV-2 Infections in Engineered Human Tissues Using Clinical-Grade Soluble Human ACE2. Cell. 2020;181(4):905-913.e7. doi:10.1016/j.cell.2020.04.004
52. Sharma A, Garcia G, Wang Y, et al. Human iPSCDerived Cardiomyocytes Are Susceptible to SARSCoV-2 Infection. Cell Reports Med. 2020;1(4). doi:10.1016/j.xcrm.2020.100052

53. Poissy J, Goutay J, Caplan M, et al. Pulmonary Embolism in Patients with COVID-19: Awareness of an Increased Prevalence. Circulation. 2020;142(2):184-186. doi:10.1161/ CIRCULATIONAHA.120.047430

54. Valtueña J, Martínez-García G, Ruiz-Sánchez D, et al. Vascular obliteration because of endothelial and myointimal growth in COVID-19 patients. Int J Dermatol. Published online 2020. doi:10.1111/ ijd. 15300

55. Zimna A, Kurpisz M. Hypoxia-Inducible factor-1 in physiological and pathophysiological angiogenesis: Applications and therapies. Biomed Res Int. 2015;2015. doi:10.1155/2015/549412 